\title{
PROVA BRASIL E DESEMPENHO EM LÍNGUA PORTUGUESA: Um estudo com escolas paranaenses
}

\author{
Cristina Cerezuela Jacobsen \\ Universidade Estadual de Maringá, UEM \\ criscerezuela@hotmail.com \\ Nerli Nonato Ribeiro Mori \\ Universidade Estadual de Maringá, UEM \\ nnrmori@uem.br
}

\section{RESUMO:}

Trata de uma investigação acerca dos fatores determinantes do desempenho de alunos de $4^{\mathrm{a}}$. série do ensino básico na Prova Brasil. Os dados foram colhidos por meio de entrevistas semi-estruturadas e análise dos planos e diários dos docentes de seis escolas paranaenses que apresentaram os maiores e menores índices em Língua Portuguesa na avaliação realizada em 2007. Das três escolas com piores resultados, em duas delas houve falhas na aplicação da prova, inclusive com troca de gabaritos por parte dos aplicadores. Todavia, o fator preponderante para o baixo desempenho dos alunos é que eles não tinham os conhecimentos exigidos. Por outro lado, nas escolas com índices mais altos, verificamos um trabalho pedagógico sistematizado de ensino dos conteúdos. Além disso, os professores demonstraram maior conhecimento que o primeiro grupo sobre a avaliação e os resultados alcançados por sua escola. Os resultados confirmam a importância do contexto socioeconômico em que os alunos estão inseridos, da formação dos professores e também do processo de aplicação das avaliações em larga escala. No entanto, o mais forte determinante do desempenho das unidades escolares é o trabalho pedagógico intencional e sistematizado dos conteúdos de Língua Portuguesa.

Palavras-chave: Prova Brasil. Língua Portuguesa. Trabalho pedagógico.

\section{“BRASIL" TEST AND PERFORMANCE IN PORTUGUESE LANGUAGE: a study with schools from Paraná State}

\begin{abstract}
:
This research is about an investigation on the determinant factors of performance of students in the 4th grades of basic education in a Braziliam examination. The data were collected through semi-structured interviews and analysis of plans and diaries of teachers from six schools in Paraná State with highest and lowest rates in Portuguese Language in the evaluation in 2007. From the three schools with the worst results in two of them there were failures in the application of the test, including exchange of the test answer sheet by the applicators. However, the predominant factor for the low performance of students is that they did not have the required knowledge. On the other hand, in the schools with higher rates, we observed a teaching job in systematic program of teaching of content. Moreover, the teachers demonstrated greater knowledge than the former group on the evaluation and the results achieved by their schools. The results confirm the importance of the socioeconomic context in which the students are present, the training of teachers and also the implementation process of large-scale assessments. Nevertheless, the strongest determinant of the performance of each school is the intentional and systematic educational work of the contents of the Portuguese language.
\end{abstract}

Keywords: "Brasil" Test. Portuguese Language. Pedagogical work. 


\section{Introdução}

A meta do governo brasileiro é atingir em 2021 os índices máximos definidos para o Ensino Básico. Para acompanhar o processo, o Ministério da Educação realiza, a cada dois anos, uma avaliação denominada Prova Brasil, voltada para as áreas de Língua Portuguesa e Matemática. São coletados dados sobre a capacidade dos alunos em leitura e resolução de problemas. Além dos testes, os alunos respondem um questionário com questões sociais e culturais relacionadas ao contexto no qual o aluno está inserido. Partimos do pressuposto de que a análise dos resultados das provas dos alunos não contribui por si só para a melhoria do desempenho; é necessária a identificação das causas das dificuldades dos alunos e, com base nesse conhecimento, estabelecer formas de intervenção para a melhoria da qualidade do ensino.

Assim, realizamos uma investigação acerca dos fatores determinantes do desempenho em Língua Portuguesa de alunos de $4^{\mathrm{a}}$. série do ensino básico na Prova Brasil, buscando responder a seguinte questão: o que está sendo avaliado em Língua Portuguesa pela Prova Brasil e quais relações podemos estabelecer entre os conteúdos avaliados e os previstos nos planos de trabalho docente?

Os dados foram colhidos por meio de entrevistas semi-estruturadas com professores e gestores, bem como de análise dos planos e diários dos docentes de seis escolas paranaenses que apresentaram os maiores e menores índices em Língua Portuguesa na avaliação realizada em 2007.

Para a apresentação do trabalho realizado, discutimos inicialmente as avaliações brasileiras atuais de larga escala e, de modo mais específico, o nosso objeto de estudo, a Prova Brasil. Na sequência, apresentamos os procedimentos metodológicos para a coleta de dados e a análise dos dados alcançados.

\section{Políticas públicas de avaliação da educação básica}

Atualmente são realizadas seis avaliações em larga escala no Brasil, todas sob a responsabilidade da Diretoria de Avaliação da Educação Básica (DAEB), vinculada ao Instituto Nacional de Estudos e Pesquisas Educacionais Anísio Teixeira (INEP). São elas: o Programa Internacional de Avaliação de Alunos (PISA); o Exame Nacional do Ensino Médio (ENEM); o Exame Nacional para Certificação de Competência de Jovens e Adultos (ENCCEJA); a Provinha Brasil; o Sistema Nacional de Avaliação da Educação Básica (SAEB) e a Prova Brasil.

O INEP é uma autarquia federal vinculada ao Ministério da Educação (MEC), cujo objetivo é promover estudos, pesquisas e avaliações sobre o Sistema Educacional Brasileiro com a intenção de subsidiar a formulação e implementação de políticas públicas para a área educacional. Conforme um documento publicado, o INEP realiza levantamentos estatísticos e avaliativos em algumas etapas da educação básica, assim como na modalidade de educação de jovens e adultos. (BRASIL, 2008).

O Programme for International Student Assessment (PISA) é um programa de avaliação internacional, desenvolvido pelos países participantes da Organização para a Cooperação do Desenvolvimento Econômico (OCDE). Ela é realizada a cada três anos e tem como objeto o desempenho de alunos na faixa etária de 15 anos nas áreas de Leitura, 
Matemática e Ciências. Como informa Stoco (2006), o Brasil passou a participar do exame a partir do ano de 2000 .

O ENEM é um exame anual, individual e de caráter voluntário. (BRASIL, 2008). Para Castro (1999), além de o aluno poder realizar uma auto-avaliação de seus conhecimentos, ele obtém parâmetros para a continuidade dos estudos ou para o ingresso no mercado de trabalho. Importante lembrar que a implantação desta avaliação contribuiu para discussões acerca de mudanças na forma de ingresso no Ensino Superior.

O ENCCEJA é um exame nacional, cujo objetivo principal é "[...] avaliar as competências e habilidades básicas de jovens e adultos que não tiveram acesso aos estudos ou não puderam continuá-los na idade própria." (BRASIL, 2008, p. 15). O participante do ENCCEJA se inscreve por áreas, sendo possível obter certificação em cada prova. As certificações são feitas diretamente nas secretarias municipais e estaduais de educação que aderirem ao exame.

Consta em documento oficial que "[...] a Provinha Brasil foi criada em consonância com o objetivo do Plano de Desenvolvimento da Educação (PDE) do MEC de viabilizar ações que contribuam para equidade e a qualidade da educação pública brasileira." (BRASIL, 2008, p. 15). Ela está voltada para alunos que estão no início do $2^{\circ}$ ano do Ensino Fundamental e, por enquanto, só existe avaliação com enfoque na alfabetização e ao início do letramento, mas o INEP planeja uma Provinha voltada para o pensamento lógico matemático.

A Prova Brasil e o SAEB são dois exames complementares que compõem o Sistema de Avaliação da Educação Básica. As primeiras discussões sobre a criação e implementação das avaliações em larga escala no Brasil ocorreram no período entre 1985 e 1986. (BRASIL, 2008; RODRIGUES, 2006). De acordo com Castro (1999), o Brasil, e igualmente outros países em desenvolvimento, naquela época, necessitavam de estratégias para promover a melhoria da qualidade do ensino ofertado. Em outras palavras, havia necessidade de "[...] articulação, de construção de consenso e de tomada de decisão a respeito dos rumos da educação nacional.” (PESTANA, 1998, p. 66).

De acordo com Kuenzer (2002), as mudanças no mundo do trabalho ocorridas na década de 1990 e advindas do neoliberalismo, estabeleceram novas demandas do sistema capitalista sobre a escola. As avaliações em larga escala se constituem em uma exigência das agências internacionais pautadas nesse novo paradigma. Em consonância com as exigências estabelecidas pela reestruturação das relações entre capital e trabalho, dois fatores opostos se sobrepõem na Lei de Diretrizes e Bases da Educação Nacional (LDBEN). Por um lado, a descentralização relacionada à minimização do poder do Estado atribui autonomia às escolas; por outro, institui a avaliação externa desenvolvida pelo próprio Estado.

Além da regulação do Sistema Nacional de Avaliação, o contexto abriga, também, as políticas de financiamento do Banco Mundial. Como não poderia deixar de ser o banco, como uma agência financiadora, estabelece as linhas gerais relativos àquilo que financia, e assim, recomenda a necessidade da eficiência produtiva, da relação com o mercado, da gratuidade da escolaridade básica, da semiprivatização do ensino superior público, e até mesmo, dos subsídios relativos ao programa Bolsa-Escola para as crianças carentes. Nesse sentido, construindo uma ligação estreita entre os resultados das avaliações e os financiamentos, estabelece relações de controle e o tipo de racionalidade econômica que deseja. (DALBEN, 2002, p. 27). 
Esse cenário revela intenções que privilegiam a produtividade e o estabelecimento de políticas focalizadas nos aspectos vinculados às leis do mercado. Para essa autora, a avaliação em larga escala tem por objetivo ratificar o controle político das instituições e dos sistemas. O questionamento do Banco Mundial baseava-se no argumento de que não existiam informações referentes ao desempenho dos sistemas de ensino em decorrência dos investimentos realizados.

Todo debate ocorrido ao longo dos anos de 1980 e 1990 esteve pautado pela necessidade de responder ao "[...] padrão de qualificação emergente no contexto de reestruturação produtiva e de globalização da economia, ocupando lugar de destaque nas políticas educacionais." (OLIVEIRA, 2001, p. 105). A elaboração de propostas para superar os problemas da insuficiência da universalização da educação básica, que é função do poder público, foi uma forma de atender as novas necessidades do modo capitalista de produção.

É nesse contexto que, em 1988, o MEC instituiu o Sistema de Avaliação da Educação Primária (SAEP). Com as alterações da Constituição Federal (BRASIL, 1988), passou a denominar-se Sistema Nacional de Avaliação da Educação Básica (SAEB). A primeira aplicação do SAEB foi em 1990 e as especificidades do levantamento eram: avaliar somente a rede pública do Ensino Fundamental, as séries contempladas para serem avaliadas nas áreas de Língua Portuguesa, Matemática e Ciências eram a $1^{\mathrm{a}}$, a $3^{\mathrm{a}}$, a $5^{\mathrm{a}}$ e a $7^{\mathrm{a}}$ séries. Nesses mesmos moldes, ainda ocorreu a avaliação de 1993. (ARAÚJO; LUZIO, 2005; DALBEN, 2002; BRASIL, 2008; FERRÃO et al., 2001; FREITAS, 2007).

O objetivo do MEC era "[...] oferecer subsídios para a formulação e reformulação e monitoramento de políticas públicas, contribuindo, dessa maneira, para a melhoria da qualidade do ensino brasileiro" (BRASIL, 2008, p. 12). Rodrigues (2006, p. 46) destaca que a primeira finalidade do SAEB era obter resultados sobre a qualidade do ensino ao longo dos anos e identificar os fatores que contribuem para esses índices, e a segunda "[...] monitorar o avanço alcançado pelos programas e pelas políticas governamentais em relação às metas educacionais". Em outras palavras, a avaliação se configura como um instrumento de acompanhamento da educação; para além da verificação do desempenho educacional, ela pode contribuir para o estabelecimento de metas para a qualificação pretendida.

Em relação ao tipo de homem a ser formado, enquanto o governo está preocupado com a formação para o trabalho, entendemos que esta deve ser para a vida. Pela organização e reestruturação do capital, a formação não garante a empregabilidade e não garante os padrões mínimos de sobrevivência.

A consumação da nova ordem mundial determinada pela reestruturação do capital, conhecida popularmente como globalização, exige novos padrões de produção e de consumo, intensificando a competição internacional. No geral, as políticas governamentais propõem medidas educacionais para a força de trabalho, a adaptabilidade às mudanças, a condição de constante aprendizagem e resolução de problemas imediatos.

Para Batista (2006, p. 82), ocorre o deslocamento do conceito de qualificação para o de competências. "A negação da qualificação e a afirmação da noção de competências inserem-se na perspectiva neoliberal que elege o indivíduo como o sujeito principal das relações sociais [...]". Esse contexto dificulta a organização em coletividade e aumenta a competitividade cunhada no mito de que cada um é responsável por superar sua condição e ocupar posição no mercado de trabalho.

Conforme estudos de Castro (1999), o SAEB é aplicado a alunos da série em final de ciclo do Ensino Fundamental, ou seja, $5^{\circ}$ e $9^{\circ}$ ano e no final do Ensino Médio, para alunos da $3^{\text {a }}$ série. Se formos destacar seus objetivos específicos, podemos citar: 
Identificar os problemas do ensino e suas diferenças regionais;

Oferecer dados e indicadores que possibilitem uma maior compreensão dos fatores que influenciam o desempenho dos alunos;

Proporcionar aos agentes educacionais e à sociedade uma visão dos resultados dos processos de ensino e aprendizagem e das condições em que são desenvolvidos;

Desenvolver competência técnica e científica na área de avaliação educacional, ativando o intercâmbio entre instituições educacionais de ensino e pesquisa;

Consolidar uma cultura de avaliação nas redes e instituições de ensino. (FERRÃO et al., 2001, p. 112).

Para alcançar esses objetivos, são empregados instrumentos específicos, como provas que mensuram o conhecimento acadêmico e questionários para alunos, professores e gestores educacionais, com o intuito de investigar fatores intra e extra-escolares. É um sistema de monitoramento contínuo que pode oferecer subsídios para o delineamento de políticas educacionais de transformação do cenário educacional.

\section{A Prova Brasil}

A Prova Brasil é um instrumento para coletar dados sobre a qualidade do ensino e da aprendizagem da educação brasileira, abrangendo as esferas municipais e estaduais. Ao ampliar a amostragem do SAEB, a Prova Brasil, além de exibir os desempenhos da federação, das regiões e dos estados, ampliou a verificação para as cidades e escolas.

De acordo com os documentos do MEC (BRASIL, 2007, 2008) e conforme explica Delmanto et al. (2007), esse exame é composto de testes que avaliam Língua Portuguesa e Matemática. A primeira área de conhecimento permite mensurar a capacidade de leitura do educando, e a segunda, a capacidade de resolução de problemas.

A Prova Brasil é parte integrante do Índice de Desenvolvimento da Educação Básica (IDEB). Este índice é uma forma de mensuração que associa os resultados da Prova Brasil com as informações sobre o rendimento escolar dos alunos, sua taxa de aprovação, e determina a qualidade da educação baseado nesses fatores. (FERNANDES, 2007).

\section{Procedimentos metodológicos}

De acordo com o site oficial do MEC, participaram da Prova Brasil um total de 2.189 (duas mil cento e oitenta e nove) escolas das séries iniciais do Ensino Fundamental. O Estado do Paraná, na edição de 2007, obteve um desempenho em Língua Portuguesa polarizado pela nota mínima de 124,44 (cento e vinte quatro vírgula quarenta e quatro) e pela máxima de 240,53 (duzentos e quarenta e cinquenta e três).

Utilizamos como instrumento de pesquisa um roteiro de entrevista semiestruturada para o docente e o gestor escolar, constando de perguntas agrupadas em cinco categorias, a saber: caracterização do sujeito, formação continuada, contexto escolar e Prova Brasil, contexto de sala de aula e Prova Brasil e expectativas do professor em relação à avaliação. Foram analisados também planos de trabalho docente e registros dos conteúdos nos diários de classe. 
Os resultados do desempenho em Língua Portuguesa na Prova Brasil no ano de 2007 foram os determinantes para a seleção da amostragem. Assim, mapeamos os resultados de todas as escolas paranaenses para identificarmos os três desempenhos de cada uma das duas extremidades. Em outras palavras, as três notas mais altas e as três mais baixas. Nestas condições, apresentamos o projeto de pesquisa às escolas e as convidamos a participarem por meio da anuência do Termo de Consentimento Livre e Esclarecido. As seis escolas pertencem às regiões de abrangência dos Núcleos Regionais de Educação de Curitiba, Londrina, Pato Branco e Wenceslau Braz.

O desempenho paranaense na avaliação de 2007 foi superior à média brasileira. $\mathrm{O}$ gráfico a seguir representa a superação dos índices tanto das escolas das esferas municipais quanto das estaduais.

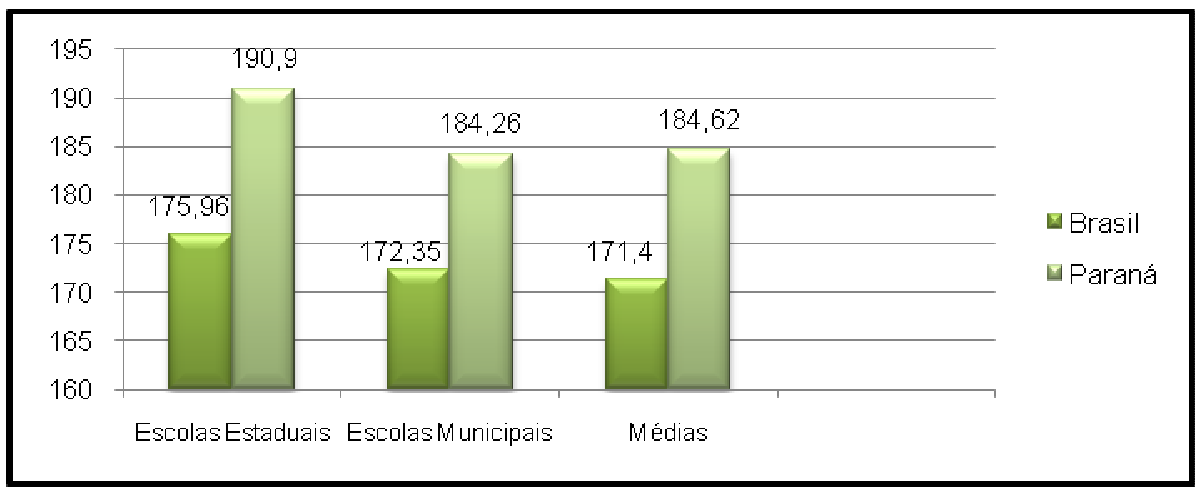

Gráfico 1 - Desempenho Paranaense Prova Brasil 2007

Fonte: Brasil (2009).

O IDEB previsto para o Paraná no ciclo de avaliação de 2007 era de 4,7 e o Estado atingiu 5,0 nas redes estadual, municipal e privada, valor equivalente ao previsto para o ano de 2009. As metas, de acordo com o MEC (BRASIL, 2009), indicam o caminho traçado para a evolução dos índices em direção às médias dos países para que o Brasil atinja o patamar educacional que têm hoje a média dos países com maior desenvolvimento. Em termos numéricos, isso significa evoluir da média nacional de 3,8, registrada em 2005, para 6,0 em 2021.

Mais que um indicador estatístico, ele é definido nas políticas educacionais como um orientador para a qualidade da educação tanto no âmbito nacional quanto no dos estados, municípios e escolas. Sua estrutura, além de viabilizar o diagnóstico atualizado da situação educacional, estabelece a projeção de metas individuais intermediárias com vista ao incremento da qualidade do ensino.

As metas foram planejadas por biênio, num período compreendido de 2007 a 2021. Elas são diferenciadas para cada rede e escola; para o Estado do Paraná foram estabelecidos os seguintes índices:

\begin{tabular}{|c|c|c|c|c|c|c|c|c|}
\hline \multicolumn{1}{|l|}{ Projeções } \\
\hline Ano & 2007 & 2009 & 2011 & 2013 & 2015 & 2017 & 2019 & 2021 \\
\hline Meta & 4,7 & 5,0 & 5,4 & 5,6 & 5,9 & 6,2 & 6,4 & 6,6 \\
\hline
\end{tabular}

Quadro 1 - Projeções do INEP para o Estado do Paraná

Fonte: Brasil (2009) 
O objetivo nacional é que a educação brasileira chegue à meta 6,0 em 2022, ano do bicentenário da Independência. Para aqueles que já atingiram esses índices, a ordem é de superação e auxílio mútuo entre as diferentes instâncias governamentais.

No próximo gráfico demonstramos o IDEB previsto para o ano de 2007 para cada uma das unidades escolares pesquisadas e suas respectivas médias.

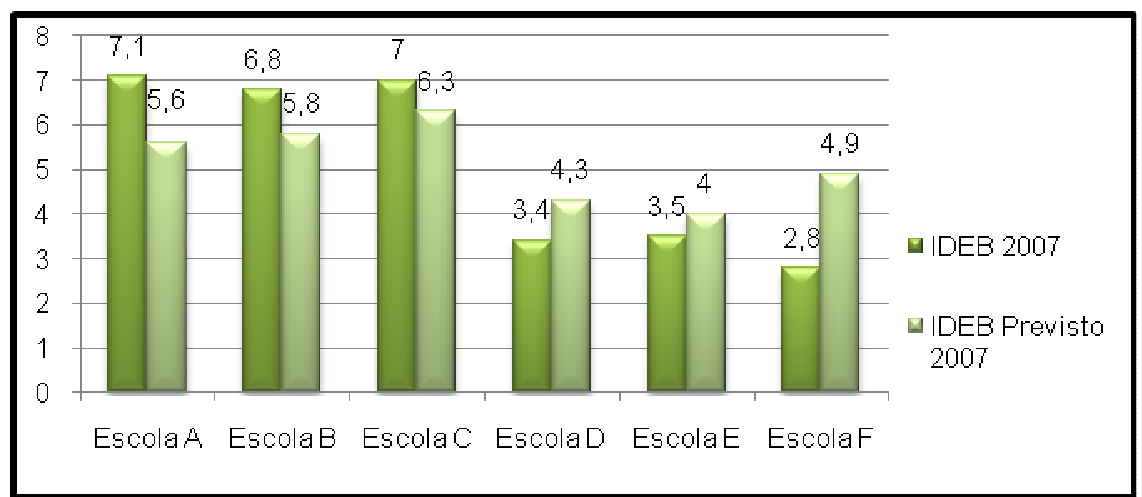

Gráfico 2 - IDEB Previsto e IDEB Real de 2007

Fonte: Brasil (2009).

Os três melhores desempenhos superaram as expectativas delimitadas pelo IDEB, enquanto os três desempenhos mais baixos ficaram aquém do mínimo previsto. Se calcularmos em porcentagem de desenvolvimento, a escola "A" apresentou um índice $21 \%$ superior ao esperado pelo MEC; e a escola " $F$ " apresentou um índice 42,8\% inferior ao estabelecido.

Como já mencionado, as metas são diferenciadas para os estados e para as escolas. Na sequência apresentamos as projeções para as escolas investigadas.

\begin{tabular}{|l|c|c|c|c|c|c|c|}
\hline \multicolumn{7}{|c|}{ Projeções } \\
\hline Ano & 2009 & 2011 & 2013 & 2015 & 2017 & 2019 & 2021 \\
\hline Escola A & 5,9 & 6,2 & 6,4 & 6,7 & 6,9 & 7,1 & 7,3 \\
\hline Escola B & 6,1 & 6,4 & 6,6 & 6,9 & 7,1 & 7,2 & 7,4 \\
\hline Escola C & 6,6 & 6,9 & 7,1 & 7,3 & 7,4 & 7,6 & 7,8 \\
\hline Escola D & 5,3 & 5,6 & 5,9 & 6,1 & 6,4 & 6,6 & 6,8 \\
\hline Escola E & 4,4 & 4,8 & 5,0 & 5,3 & 5,6 & 5,9 & 6,1 \\
\hline Escola F & 4,6 & 5,0 & 5,3 & 5,6 & 5,8 & 6,1 & 6,4 \\
\hline
\end{tabular}

Quadro 2 - Projeções do INEP para as Escolas Pesquisadas

Fonte: Brasil (2009)

O desempenho paranaense, mesmo sendo superior à média brasileira, ainda apresentou discrepância entre suas próprias cidades e unidades escolares. No Paraná, a diferença entre a melhor nota e a nota mais baixa chega a ser de praticamente o dobro.

Ao analisarmos os planos de trabalho docente das escolas entrevistadas, averiguamos que os três melhores desempenhos apresentam planejamento e registro de atividades envolvendo os descritores e os tópicos das Matrizes de Referências da Prova Brasil. Das três escolas com os desempenhos mais baixos do Paraná, uma delas não apresentou planejamento e registro atualizado com os conteúdos das matrizes. As outras duas evidenciaram um trabalho voltado para esses conteúdos e ainda assim estão situadas no grupo com os piores desempenhos; segundo informações dos gestores escolares, esse 
fato foi determinado por uma falha no processo de aplicação. Os aplicadores teriam trocado os gabaritos das provas de Língua Portuguesa com os de Matemática, o que foi decisivo para a baixa classificação das escolas E e F.

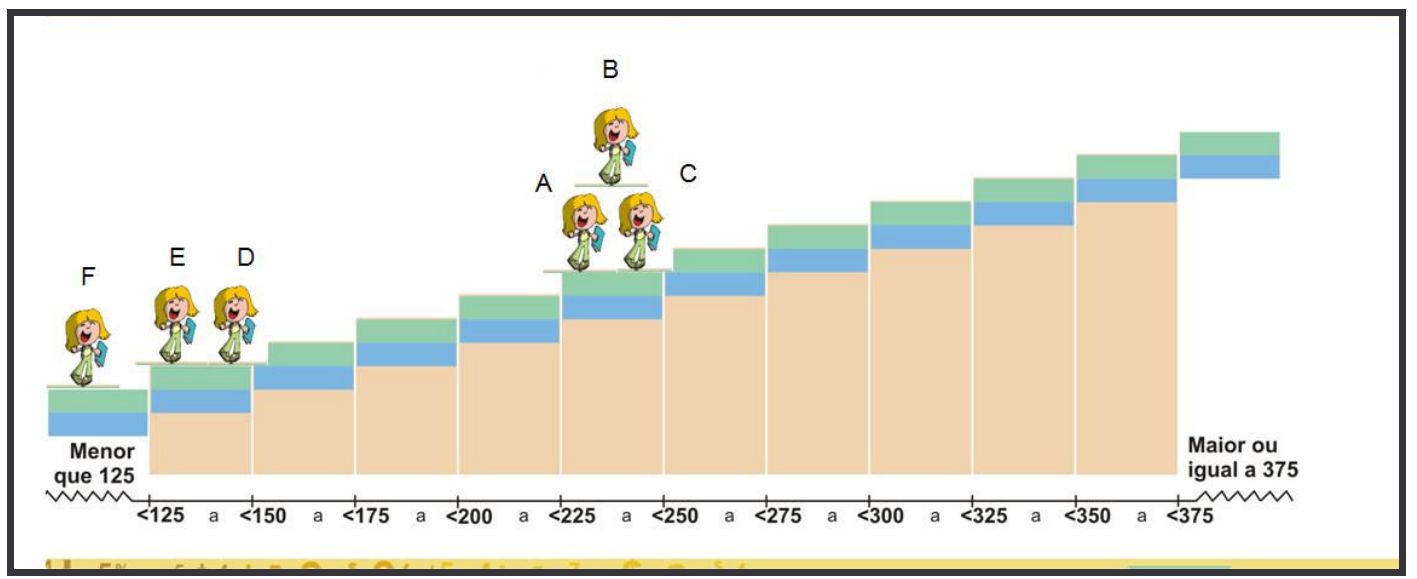

Figura 1 - Visualização Geral do Desempenho das Escolas Pesquisadas

Fonte: Adaptado de Brasil (2009).

Os melhores resultados paranaense embora sejam superiores à média nacional, ainda se encontram em nível mediano da escala de desempenho. Os melhores ainda precisam avançar na apropriação e objetivação dos conteúdos de Língua Portuguesa. Ao fundamentarmos nossa discussão em Sforni e Galuch (2006), questionamos se as escolas estão conseguindo ampliar os conceitos espontâneos dos indivíduos para que eles tenham condições de se apropriar dos conceitos científicos de forma significativa. As escolas apresentaram condições pedagógicas, políticas, físicas e financeiras para oferecer aos seus alunos possibilidades iguais de formação? As escolas estão preparando os alunos para pensar ou reproduzir, para raciocinar ou para executar tarefas? Em sala de aula os alunos realizam atividades que envolvem atividades complexas do pensamento?

São questões importantes, visto que avaliações em grande escala como a Prova Brasil exigem inferir o significado de uma palavra em um contexto, o que demanda um pensamento mais complexo, para além da automação e reprodução, como é frequente em exercícios de interpretação.

Sobre o processo de humanização, Leontiev (2004) apresenta em seus estudos questões cruciais relacionadas ao processo dialético entre o homem e a cultura. A apropriação do mundo exterior objetivo é dialética. Ao mesmo tempo em que se apropria e modifica a cultura e a sociedade, o homem forma e transforma as suas faculdades. Esse processo de apropriação e desenvolvimento só é verdadeiro quando ele pode aplicar em atividade a objetivação apropriada.

[...] a experiência sócio-histórica da humanidade se acumula sob a forma de fenômeno do mundo exterior objetivo. Esse mundo, o da indústria, das ciências e da arte é a expressão da história humana; é o saldo da sua transformação histórica. [...] Para se apropriar dos objetos ou dos fenômenos que são o produto do desenvolvimento histórico, é necessário desenvolver em relação a eles uma atividade que se reproduza, pela sua forma, os traços essenciais da atividade encarnada, acumulada no objeto. (LEONTIEV, 2004, p. 286). 
A apropriação, de fato, somente se realiza quando a utilização do objeto é adequada. Se o indivíduo tem acesso aos instrumentos físicos ou simbólicos, mas não obtém a forma adequada para empregá-los em sua vida, ou não alcança proveito em seu desenvolvimento para ampliar a apropriação dos bens históricos, ele não se apropriou de fato e de forma plena dessa cultura.

A intencionalidade de trazer essas considerações para este texto é para dar relevo à importância da discussão acerca dos desempenhos das escolas paranaenses nas avaliações da Prova Brasil. Quando nos deparamos com os resultados dessas avaliações nacionais em larga escala e nos defrontamos com índices aquém do esperado, perguntamo-nos se o sistema educacional está cumprindo sua função social.

Com base em Leontiev (2004), indagamos se os alunos estão se apropriando da objetivação atrelada ao objeto da linguagem escrita.

Os resultados da Prova Brasil no ano de 2007 evidenciam que o educando tem acesso ao instrumento físico da leitura - os livros - mas não se apropria da objetivação encarnada e acumulada no objeto da leitura. Ele sabe ler, já frequentou por quatro anos, no mínimo, os bancos escolares. Ainda assim, não consegue usufruir do conhecimento que lhe daria o entendimento dos textos nos diferentes contextos e significados, ou seja, que produza um pensamento mais abstrato.

Outra inferência que podemos fazer em relação a essa discussão é que há lacunas entre o avaliado na Prova Brasil e o ensinado em sala de aula. Para o educando se apropriar de um bem cultural, é necessário estabelecer relação com os fenômenos do mundo circundante com outros homens, num processo de comunicação. Como explica Leontiev (2004), a criança, num processo educacional, aprende a atividade adequada.

Perguntamos aos entrevistados quais os fatores determinantes dos resultados na Prova Brasil e lhes solicitamos um parecer geral, desvinculado do desempenho de sua escola, ou seja, voltado para a dimensão nacional. Obtivemos como principal resposta o trabalho docente eficiente e com foco no ensino dos conteúdos. Outro fator ressaltado pelos entrevistados foi a experiência de atividades semelhantes aos itens da Prova. Segundo eles, os alunos precisam desenvolver o conhecimento das possibilidades de exploração de um texto.

Para os coordenadores pedagógicos das secretarias municipais, o foco deve ser o conteúdo e os objetivos específicos traçados pelos projetos político-pedagógicos e desenvolvidos no cotidiano escolar. Para a gerente do Ensino Fundamental do município de três escolas investigadas nesta pesquisa, é necessário haver unidade na rede entre as escolas, cabendo à secretaria municipal discutir junto com os professores e gestores escolares a questão do ensino no interior da escola e estabelecer metas coletivas para a educação como um todo.

Uma única resposta se distanciou dessa discussão, ao afirmar que o determinante do desempenho da escola é o conhecimento dos alunos sobre sua região. Para ser justa, a prova deveria ser adaptada a cada região do país e dos municípios. Para a pedagoga da escola "D", a Prova deveria pautar-se pelas diferenças culturais.

Sawaya (2002) faz uma crítica aos que explicam o fracasso escolar com base na "teoria das diferenças culturais". A autora pontua que nessa teoria

Afirma-se que as crianças de camadas populares falam uma linguagem diferente das outras classes sociais, resolvem problemas escolares de maneira distinta, possuem valores, padrões culturais que diferem substancialmente de outras crianças e daqueles propostos pela escola e pela sociedade em que vivem. Assim, os problemas escolares que resultariam em fracasso se devem a uma disparidade cultural entre os 
padrões de classe média que organizam as práticas e as concepções da escola e aqueles apresentados por essas crianças. [...] Esses indivíduos, privados socialmente, pertenceriam a uma cultura diferente, desconsiderada e desvalorizada pela escola (SAWAYA, 2002, p. 200).

Basear a prática pedagógica no pressuposto das diferenças seria reduzir o processo educativo e anular sua contribuição à humanização dos indivíduos. Para promover a apropriação dos conhecimentos, é preciso ir além do saber cotidiano e do que é próprio da condição geográfica ou social do aluno.

Pensar uma avaliação de larga escala nacional fragmentada em conteúdos regionais ou diferenciada de acordo com a classe econômica dos alunos seria negar à escola a sua função. Para Saviani (2003), o conteúdo da educação é determinado pela sociedade, porque esta faz parte do processo histórico, mas toda proposta pedagógica deve avançar para além da prática social inicial.

Em complemento a esta questão, perguntamos se as escolas poderiam elencar características específicas que determinaram os resultados da Prova Brasil em 2007. As escolas "A", "B", "C" e "D" reiteraram a resposta da pergunta anterior. As escolas "E" e "F" alegaram que o fator externo ao cotidiano escolar (o processo de aplicação e a troca de gabaritos) foi a causa do baixo desempenho.

Iniciamos a investigação com o questionamento sobre os conteúdos avaliados em Língua Portuguesa pela Prova Brasil e possíveis relações entre eles e os previstos nos planos de trabalho docente. Para os entrevistados cujo desempenho na avaliação de 2007 foi bom, é imprescindível um trabalho com foco nos conteúdos contemplados na avaliação. Não obstante, em nosso entendimento, a prática pedagógica nessa área de conhecimento não se reduz ao ensino desses conteúdos, mas deve abarcar os eixos estruturantes da disciplina de Língua Portuguesa, que são leitura, escrita e oralidade.

\section{À guisa de conclusão}

Com base nos dados colhidos na pesquisa e os estudos realizados, concluímos que a Prova Brasil constitui um importante instrumento para coletar dados sobre a qualidade do ensino e da aprendizagem da educação brasileira. Todavia, atualmente ainda apresenta muitas falhas; assim, para atingir os objetivos propostos, precisa rever a maneira como são selecionados seus aplicadores e promover o treinamento adequado para esse processo.

Uma constatação básica desta pesquisa é a importância do trabalho pedagógico desenvolvido nas escolas. Aquelas que conduzem em seu cotidiano um trabalho sistematizado, específico e intencional do ensino dos conteúdos apresentam melhores desempenhos na Prova Brasil. Reiteramos nossa defesa de que a escola cumpre seu papel quando, de fato, ensina. Em síntese, ela pode desenvolver sua função política de humanização se promover o ensino e a apropriação dos conhecimentos elaborados e acumulados pela sociedade.

\section{REFERÊNCIAS}

ARAÚJO, C. H.; LUZIO, N. Avaliação da educação básica: em busca da qualidade e eqüidade no Brasil. Brasília, DF: Instituto Nacional de Estudos e Pesquisas Educacionais Anísio Teixeira, 2005. 
BATISTA, R. L. A panacéia das competências: uma problematização preliminar. In: ALVES, G. et al. (Org.). Trabalho e educação: contradições do capitalismo. Maringá, PR: Praxis, 2006. p. 82-114.

BRASIL. Ministério da Educação. Instituto nacional de estudos e pesquisas educacionais Anísio Teixeira. 2009. Disponível em: www.inep.gov.br. Acesso em: 06 jun. 2009.

BRASIL. Ministério da Educação. PDE: plano de desenvolvimento da educação: prova Brasil: ensino fundamental: matrizes de referência, tópicos e descritores. Brasília: MEC, SEB, INEP, 2008.

BRASIL. Ministério da Educação. Prova Brasil: avaliação do rendimento escolar, ensino fundamental, matrizes de referências, tópicos e descritores. Brasília: Instituto Nacional de Estudos e Pesquisas Educacionais Anísio Teixeira, 2007.

CASTRO, M. H. G. de. Educação para o século XXI: o desafio da qualidade e da equidade. Brasília: Instituto Nacional de Estudos e Pesquisas Educacionais Anísio Teixeira, 1999.

DALBEN, Â. I. L. de F. Das avaliações exigidas às avaliações necessárias. In: VILLAS BOAS (Org.) Avaliação: políticas e práticas. Campinas, SP: Papirus, 2002. p. 13-42 (Coleção Magistério: Formação e Trabalho Pedagógico).

DELMANTO, D. et al. Prova Brasil na escola: material para professores, coordenadores pedagógicos e diretores de escolas de ensino fundamental. São Paulo: Centro de Estudos e Pesquisas em Educação, Cultura e Ação Comunitária, 2007.

FERNANDES, R. Índice de desenvolvimento da educação básica. Brasília: Instituto Nacional de Estudos e Pesquisas Anísio Teixeira, 2007. 26 p. (Série documental. Textos para discussão; 26).

FERRÃO, M. E. et al. O SAEB: sistema nacional de avaliação da educação básica: objetivos, características e contribuições na investigação da escola eficaz. Revista Brasileira de Estudos de População, Rio de Janeiro, v. 18, n. 1-2, p. 111-130,

FREITAS, D. N. T. A avaliação da educação básica no Brasil: dimensão normativa, pedagógica e educativa. Campinas, SP: Autores Associados, 2007. (Coleção educação contemporânea).

KUENZER, A. Z. Trabalho pedagógico: da fragmentação à unitariedade possível. In: AGUIAR, S. A. M.; FERREIRA, C. S. N. (Org.). Para onde vão a orientação e a supervisão educacional? Campinas: Papirus, 2002. p. 47-78.

LEONTIEV, A. O desenvolvimento do psiquismo. 2. ed. São Paulo: Centauro, 2004.

OLIVEIRA, D. A. Política educacional nos anos 1990. Educação básica e empregabilidade. In: DOURADO, F.; PARO, V. H. (Org.) Políticas públicas e educação básica. São Paulo: Xamã, 2001. 
PESTANA, M. I. G. S. O sistema de avaliação brasileiro. Revista Brasileira de Estudos Pedagógicos, Brasília, v. 79, n. 191, p. 65-73, jan./abr. 1998.

RODRIGUES, M. M. M. Proposta de análise de itens das provas do SAEB sob a perspectiva pedagógica e a psicométrica. Estudos em Avaliação Educacional, São Paulo, v. 17, n. 34, p. 43-78, maio/ago. 2006.

SAVIANI, D. Escola e democracia: teorias da educação, curvatura da vara, onze teses sobre a educação política. 36. ed. rev. Campinas, SP: Autores Associados, 2003. (Coleção polêmicas do nosso tempo, v.5).

SAWAYA, S. M. Novas perspectivas sobre o sucesso e o fracasso escolar. In: OLIVEIRA, M. K. de.; REGO, T. C.; SOUZA, D. T. R. (Org.). Psicologia, educação e as temáticas da vida contemporânea. São Paulo: Moderna, 2002, p. 197-213.

SFORNI, M. S. de F.; GALUCH, M. T. B. Conteúdos escolares e desenvolvimento humano: qual a unidade? Comunicações, Piracicaba, ano 13, n. 3. p. 150-158, nov. 2006.

SOUSA, S. M. Z. L. Possíveis impactos das políticas de avaliação no currículo escolar. Cadernos de Pesquisa, São Paulo, n. 119, p. 175-190, jul. 2003.

STOCO, S. SAEB: uma análise da política. 2006. 160 f. Dissertação (Mestrado em Educação)-Universidade Estadual de Campinas, São Paulo, 2006. 